\title{
Homeopathy is not for everyone
}

Volume 2 Issue 3 - 2015

\section{Opinion}

People often ask me why isn't homeopathy medicine more spread, more accepted by majority, in short why doesn't it have more success?

This kind of question usually came from persons who are marvelled with the quick results they had, as soon they began with the homoeopathic remedy or the "little balls" as they usually said.

Against what is often said, homeopathy is not "slow" running.

Homeopathy is fast and effective, but with the right remedy.

Homeopathy is not for everyone!

It is true. And why? Because as life demands us changes, homeopathy demands also changes, even if they are tiny ones, we have to do them, and the majority of people do not want changes. Each organism has its balance, and homeopathy shows to us the way to get it and the urgency of that attitude.

Example 1: Mrs A. suffers from sinusitis but likes milk and yoghurt, (the dairy products increase the production of catarrh mainly in the nasal mucous) and don't want to stop eating those products. The homeopathic remedy will help in the acute, but when she catches another cold, she will have another crises obstructed nose, thick discharges, bad taste in the mouth, headache, etc.

Example 2: Mrs B. suffered recurrent urinary tract infections, and she loves seafood (it is one of the causes of this kind of problem) and don't want to stop eating it, so it is natural that she continued to have infections. The homeopathic remedy cures the acute situation, but if after a week or two she will eat again seafood accompanied by beer or white wine, the next day or even in the same night she will have again the urinary tract infection. These examples are simple cases because they have to do with self discipline regarding the food we eat, and everyone knows that we should have a healthy diet. But even with that knowledge, people still eat just what they like and the next day to feel sick. True, even when they know for sure that after eating seafood they will be suffering a lot, urinating blood, even so they don't give it up: "But, it's so good and I only ate one shrimp!".

And this part is the easy one!

When we begin explaining that they have to stop drink coffee, to smoke tobacco and others ... when we talk about sleeping, working and leisure habits, we already have problems. But when we talk about acceptance and change, to get at least 15 minutes per day to be alone with themselves, then we have a problem!

To explain to my students and patients how the disease "appears" I begin to say that: "as we think, we feel and we are", meaning that our
Ana Isabel Neto
International Academy of Classical Homeopathy, Portugal

Correspondence: Ana Isabel Neto, International Academy of Classical Homeopathy, R. João de Freitas Branco, 35-A, loja 2 I 500-627 Lisboa / Portugal, Tel +35 |919671080,

Email anaisabelcneto@gmail.com

Received: November 2I, 2015 | Published: January 5, 2015

way of thinking reflects in our way of feeling, and both reflect in our physical body, which works very well and can handle with our abuses, but only to a certain point. If we put together our family trends, plus what we have done throughout our lives, the result is to feel small demonstrations of discomfort, which quickly annulled with more coffee, more vitamins, more pills, and more energy drink.

And so we go indefinitely, according to each organism, till one day life makes us to stop. It is our body telling: "Enough!".

For some it will be a pharyngitis, a stomach ulcer, a depression and if not careful it can be transformed in something much more serious.

For others will be a cancer, an auto immune disease....

And all because we have not obeyed the first signs, we did not want to change, did not want to accept.

So homeopathy is only for those brave people that want/need to change their lives.

\section{Acknowledgments}

None.

\section{Conflicts of interest}

None.

\section{Funding}

None. 